\title{
Comparison of Methods for Estimating Mechanical Properties of Wood by NIR Spectroscopy
}

\author{
L. R. Schimleck $\left(\mathbb{D},{ }^{1}\right.$ J. L. M. Matos $\mathbb{D}^{2},{ }^{2}$ R. Trianoski, ${ }^{2}$ and J. G. Prata ${ }^{2}$ \\ ${ }^{1}$ Department of Wood Science and Engineering, Oregon State University, Corvallis, OR 97331, USA \\ ${ }^{2}$ Department of Wood Science and Technology, Federal University of Paraná, Curitiba, PR, Brazil
}

Correspondence should be addressed to L. R. Schimleck; laurence.schimleck@oregonstate.edu

Received 2 September 2017; Revised 17 November 2017; Accepted 5 December 2017; Published 25 February 2018

Academic Editor: Davidson Sajan

Copyright (C) 2018 L. R. Schimleck et al. This is an open access article distributed under the Creative Commons Attribution License, which permits unrestricted use, distribution, and reproduction in any medium, provided the original work is properly cited.

\begin{abstract}
Near-infrared (NIR) spectroscopy provides a rapid alternative to traditional methods of wood property assessment. For organizations who assess wood properties on a large scale, multisite, multispecies calibrations are of practical interest. We examined NIR spectroscopy for the estimation of density (at $12 \%$ moisture content), modulus of elasticity (MOE), and modulus of rupture (MOR) using clear wood samples obtained from several pine species (Pinus caribaea var. bahamensis, var. hondurensis, and var. caribaea, P. chiapensis, P. maximinoi, P. oocarpa, P. taeda, and P. tecunumanii). We compared different methodologies for collecting spectra, that is, benchtop instrument versus benchtop fiber-optic probe and field portable fiberoptic probe, and different wood surfaces (radial and transverse). Calibrations based on the benchtop instrument were superior to those obtained using the fiber-optic probe systems. Difficulty with adequately representing the sample when collecting spectra using a fiber-optic probe and lower quality spectra explain the differences among the data sets. Spectra collected from radial and transverse surfaces provided similar calibration statistics. The calibrations obtained for density $\left(R^{2}=0.81, \mathrm{SECV}=38.5 \mathrm{~kg} / \mathrm{m}^{3}\right)$ and $\operatorname{MOE}\left(R^{2}=0.81, \mathrm{SECV}=1124 \mathrm{GPa}\right)$ using benchtop instrument spectra demonstrate that it is possible to obtain general calibrations for estimating the wood properties of a number of tropical, subtropical, and temperate pine species.
\end{abstract}

\section{Introduction}

For organizations who assess wood properties on a large scale, the cost of traditional methods of analysis limits the number of samples that can be analyzed. The practical implications of such limitations are far reaching in forestry and wood product-related industries. An understanding of wood variability for a given species, that is, within trees, and within and among stands, and among different species is severely limited as is our understanding of how different environments affect wood properties and quality. Similarly, the estimation of genetic parameters for wood properties, critical to the success of tree improvement programs, is limited by the cost and time involved in determining such properties in large numbers $[1,2]$.

Efforts to lower the cost and time involved in wood property analysis have seen the development of rapid, nondestructive assessment methods. Many studies have explored near-infrared (NIR) spectroscopy as an alternative approach to traditional methods of wood property analysis [3, 4]. Reports can generally be divided into two groups, that is, those related to wood chemistry, for example, cellulose or lignin content and pulp yield, and those related to physicalmechanical properties such as density, modulus of elasticity (MOE), and modulus of rupture (MOR).

In terms of understanding the performance of lumber when used in construction, density (mass divided by volume at a given moisture content), MOE (a measure of the elastic deformation that wood undergoes when subject to an applied load), and MOR (a measure of the breaking strength of wood when subject to an applied load) are critical. Current measurement standards require destructive sampling and careful sample preparation and testing. The samples used for destructive testing, referred to as short, clear samples or static bending samples, have been utilized in a range of NIR-based research over the past twenty years. In these studies, many different NIR instruments have been utilized; however, approaches to spectral acquisition differ in two key aspects. 
The first is the spectroscopic method utilized to collect NIR spectra; either a fiber-optic probe (referred to in the following text as "Probe") was used or the surface of the wood sample was placed directly over the NIR beam ("Direct"). The second is the wood surface used for analysis. Owing to the structure of wood, a straight grain, clear wood sample has three distinct surfaces (the radial, tangential, and transverse or cross section) (Figure 1) available for testing. In addition to these differences, test sample size varied as did the size of the area analyzed by NIR. The area analyzed varied both in terms of the number of locations measured for a given piece of wood and the size of the NIR beam, as determined in the Direct approach by the aperture of the NIR instrument or a window placed over the beam and in the Probe method by the diameter of the fiber-optic probe. Table 1 provides a summary of these reports and includes species examined, wood surface utilized, size of the short, clear sample tested, method for collecting NIR spectra, number of spectra collected, and size of the NIR beam.

Comparison of different methodologies (Probe versus Direct or wood surface used for analysis) on the same set of samples is rare as are multiple species calibrations for physical-mechanical properties such as MOE and MOR. Therefore, the objectives of this study were as follows:

(i) To develop density, MOE, and MOR calibrations using a number of tropical, subtropical, and temperate pine species

(ii) To compare wood property calibrations based on NIR spectra collected using a benchtop instrument, a benchtop instrument fitted with a fiber-optic probe, and field portable instrument fitted with a fiber-optic probe

(iii) To compare wood property calibrations based on NIR spectra collected from two different wood surfaces (radial and transverse) using the three different NIR instrument options

\section{Material and Methods}

2.1. Sample Origin. The samples utilized in this study were from the plantations managed by Brazilian companies in the Center for Genetic Conservation and Improvement of Tropical Pine and Camcore (http://www.camcore.org). Pinus caribaea var. hondurensis (Sénéclauze) W.H. Barrett \& Golfari, Pinus chiapensis (Martínez) Andersen, Pinus maximinoi H.E. Moore, Pinus oocarpa Schiede ex Schltdl, Pinus taeda L., and Pinus tecunumanii F. Schwerdtf. ex Eguiluz \& J.P. Perry samples were collected from a site located in Ventania, Paraná, Brazil, while a site located in the Municipality of Itararé, São Paulo, Brazil, provided samples from the remaining species (P. caribaea var. bahamensis (Grisebach) W.H. Barrett \& Golfari and P. caribaea var. caribaea Morelet). Figure 2 shows the locations of the two plantations, while Table 2 provides a summary of site characteristics.

2.2. Sample Collection and Preparation of Samples. Five medium-sized trees of each species were selected, and

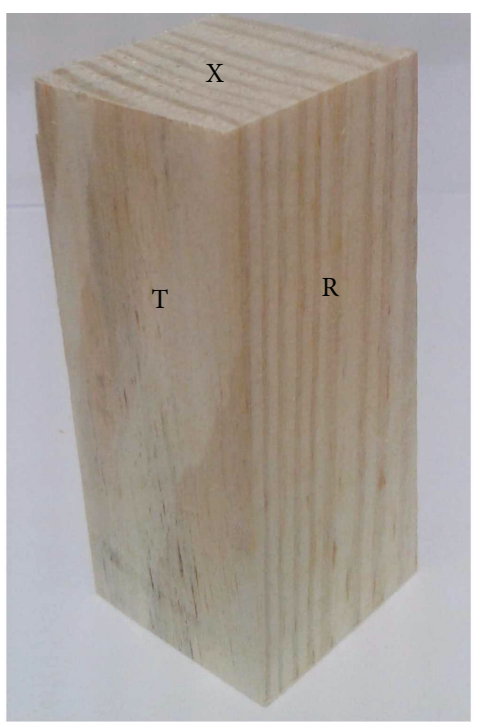

Figure 1: The three surfaces (radial, R; tangential, T; and transverse (cross-section), X) of a straight grained short, clear sample available for near-infrared (NIR) analysis. Note the arrangement of the growth rings.

diameter at breast height and total height were measured (Table 3). After felling, the length from the base of the tree to the merchantable top was measured and the tree cut into four logs of equal length $(2.5 \mathrm{~m})$. At a sawmill, a $100 \mathrm{~mm}$ thick bark-bark slab $2.5 \mathrm{~m}$ in length was cut through the pith from each log.

At the Federal University of Paraná (Curitiba, Brazil) Wood Technology Laboratory, the slabs were cut to provide clear wood samples from pith to bark with dimensions $20 \mathrm{~mm}(\mathrm{~T}) \times 20 \mathrm{~mm}(\mathrm{R}) \times 300 \mathrm{~mm}(\mathrm{~L})$. The samples were then conditioned to an equilibrium moisture content (MC) of $12 \%$, and MOE and MOR were determined using an EMIC Universal Testing Machine (EMIC Equipamentos e Sistemas de Ensaio LTDA, São José dos Pinhais, PR, Brasil) according to the COPANT standard [24]. Density of the samples was determined using the dimensions and weight of each piece at $12 \%$ MC. After completion of wood property determination, a block with dimensions $20 \mathrm{~mm}(\mathrm{~T}) \times 20 \mathrm{~mm}$ (R) $\times 20 \mathrm{~mm}$ (L) was cut from the end of each sample for NIR analysis.

2.3. Near-Infrared Spectroscopy. Diffuse reflectance NIR spectra were collected from the radial and transverse faces of each static bending sample using a Foss NIRSystems (Laurel MD, USA) Model 5000 scanning spectrometer and an ASD AgriSpec backpack portable NIR spectrometer fitted with a contact probe (approximately $25 \mathrm{~mm}$ in diameter, but with a spot size of $10 \mathrm{~mm}$ ). Spectra collected using the Foss instrument were obtained using two different methods: (1) Foss Static-samples were held in a custom-made holder that had been fitted with a $12.5 \mathrm{~mm} \times 10 \mathrm{~mm}$ Teflon mask (the mask was used to ensure that an area of constant size was analyzed) and (2) Foss Probe-NIR spectra were collected using an Optiprobe analyzer fiber-optic probe approximately $5 \mathrm{~mm}$ in diameter. Owing to the size of the ASD probe, a 
TABLE 1: Summary of publications that have utilized near-infrared (NIR) spectroscopy to estimate physical mechanical properties of short, clear samples. Information includes species examined, wood surface utilized, size of the short, clear sample tested, method for collecting NIR spectra, number of spectra collected, and size of the NIR beam. NA denotes that the information was not available in the publication. $\mathrm{R}=$ radial surface; $\mathrm{T}=$ tangential surface; $\mathrm{X}=$ transverse (or cross section) surface; $\mathrm{GR}=$ growth rings.

\begin{tabular}{|c|c|c|c|c|c|}
\hline Authors & Species & $\begin{array}{l}\text { Wood } \\
\text { surface }\end{array}$ & $\begin{array}{l}\text { Test specimen size } \\
(\mathrm{R} \times \mathrm{T} \times \mathrm{L}, \mathrm{mm})\end{array}$ & $\begin{array}{c}\text { NIR method } \\
\text { (number of spectra) }\end{array}$ & Window size \\
\hline Hoffmeyer and Pedersen (1995) [5] & Picea abies & $\mathrm{X}$ & $45,95,1800$ & Direct (NA) & $\mathrm{NA}$ \\
\hline Gindl et al. (2001) [6] & Larix decidua & $\mathrm{R}$ & $18,18,250$ & Probe (3) & $4 \mathrm{~mm}$ diam. \\
\hline Thumm and Meder (2001) [7] & Pinus radiata & $\mathrm{R}$ and $\mathrm{T}$ & $20,20,300$ & $\begin{array}{l}\text { Direct, sample } \\
\text { moving (1) }\end{array}$ & $20 \mathrm{~mm}$ \\
\hline Schimleck et al. (2001) [8] & Eucalyptus delegatensis & $\mathrm{R}$ & $20,20,300$ & Direct (1) & $5 \times 20 \mathrm{~mm}$ \\
\hline Schimleck et al. (2002) [9] & Pinus radiata & $\mathrm{R}$ & $20,20,300$ & Direct (1) & $5 \times 20 \mathrm{~mm}$ \\
\hline Via et al. (2003) [10] & Pinus palustris & $\mathrm{R}$ & $3 \mathrm{GR}, 12.7,304.8$ & Direct (2) & NA \\
\hline Kelley et al. (2004) [11] & Pinus taeda & $\mathrm{R}$ & 3GR $20-35,15,300$ & Probe (4) & $20 \mathrm{~mm}^{2}$ \\
\hline Kelley et al. (2004) [12] & 6 softwood species & $\mathrm{R}$ & $\begin{array}{c}3 \text { GR } 20-35,15,300 \text { or } \\
20,15,200\end{array}$ & Probe (4) & $20 \mathrm{~mm}^{2}$ \\
\hline Schimleck et al. (2005) [13] & Pinus taeda & $\mathrm{R}, \mathrm{X}$ & $25.4,25.4,406$ & Direct (2) & $5 \times 12.5 \mathrm{~mm}$ \\
\hline \multirow{2}{*}{ Via et al. (2005) [14] } & \multirow{2}{*}{ Pinus palustris } & \multirow{2}{*}{$\mathrm{R}$} & \multirow{2}{*}{$3 \mathrm{GR}, 12.7,304.8$} & Direct (2) & $8 \mathrm{~mm}$ \\
\hline & & & & Probe (2) & $5 \mathrm{~mm}$ \\
\hline Andre et al. (2006) [15] & Populus & $\mathrm{R}$ & $50,50,1000$ & Probe (4) & $20 \mathrm{~mm}$ diam. \\
\hline Haartveit and Flæte (2006) [16] & Picea abies & $\mathrm{X}$ & $20,20,340$ & Direct (NA) & $10 \mathrm{~mm}$ diam. \\
\hline Fujimoto et al. (2007) [17] & Hybrid larch & $\mathrm{R}$ & $20,20,320$ & Probe (2) & NA \\
\hline Fujimoto et al. (2008) [18] & Hybrid larch & $\mathrm{R}$ and $\mathrm{T}$ & $20,20,320$ & Probe (2) & NA \\
\hline Lestander et al. (2008) [19] & Pinus sylvestris & $\mathrm{X}$ & $3 \mathrm{GR}, 6.3,120.5$ & Probe (NA) & $4 \mathrm{~mm}$ diam. \\
\hline Zhao et al. (2009) [20] & Eucalyptus pellita & $\mathrm{R}$ and $\mathrm{T}$ & NA & Probe (NA) & NA \\
\hline Kothiyal and Raturi (2011) [21] & Eucalyptus tereticornis & $\mathrm{R}$ and $\mathrm{T}$ & $20,20,300$ & Direct (10) & NA \\
\hline \multirow[t]{2}{*}{ Schimleck et al. (2011) [22] } & Caesalpinia echinata & $\mathrm{X}$ & $20,20,300$ & Direct $(4,2,1)$ & $5 \times 5,5 \times 10,15 \times 15$ \\
\hline & & & & Probe (1) & $15 \times 15 \mathrm{~mm}$ \\
\hline \multirow[t]{2}{*}{ Kothiyal et al. (2014) [23] } & Eucalyptus tereticornis & $\mathrm{R}$ and $\mathrm{T}$ & $20,20,300$ & Direct (4) & $15 \mathrm{~mm}$ \\
\hline & & & & Probe (4) & $10 \mathrm{~mm}$ \\
\hline
\end{tabular}

Instruments from the following companies were utilized in the publications listed: ASD Field Spec [11, 12, 14, 15, 20, 22], Bran and Luebbe [17], Bruker $[6,18,21,23]$, FOSS [7-9, 13, 19, 22], LT industries [5], Perkin Elmer [16], and Thermo Nicolet [10, 14].

single spectrum was collected from each surface, while for the two Foss methods, two spectra were collected and averaged (Figure 3).

Spectra obtained by the Foss NIRSystems instrument were collected at $2 \mathrm{~nm}$ intervals over the wavelength range 1100 to $2498 \mathrm{~nm}$, while for the ASD instrument, the sampling interval was $2 \mathrm{~nm}$ for 1000 to $2500 \mathrm{~nm}$. The full wavelength range available was used for the Foss Direct method. Owing to noise for the fiber-optic probe systems and also for comparative purposes, data collected by both spectrometers were limited to a wavelength range of $1100-2300 \mathrm{~nm}$.

All measurements were made in a controlled environment of $40 \%$ relative humidity and a temperature of $20^{\circ} \mathrm{C}$.

2.4. Wood Property Calibrations. Wood property calibrations for three properties: density at $12 \% \mathrm{MC}$, MOE, and MOR, were developed using raw spectra, that is, no spectral pretreatments were employed. The Unscrambler software (version 9.2) and partial least squares (PLS) regression (with four cross-validation segments) were used. The software recommended the number of factors reported for each calibration. A total of 334 samples were analyzed; however, two that had very high densities were identified as outliers and were omitted from the final density models.

The standard error of calibration (SEC) (determined from the residuals from the final calibration), standard error of cross-validation (SECV) (determined from the residuals of each cross-validation phase), and the coefficient of determination $\left(R^{2}\right)$ were used to assess calibration performance. The ratio of performance to deviation $\left(\mathrm{RPD}_{\mathrm{c}}\right)$ [25], calculated as the ratio of the standard deviation of the reference data to the SECV, was also used to assess calibration performance. Determination of the RPD allowed comparison of calibrations developed for different wood properties that have different ranges in values. As this study was only concerned in comparing the relative performance of calibrations obtained using different spectroscopic approaches, it was decided to maximize the samples available for calibration and not split the datasets for calibration and prediction.

\section{Results}

3.1. Measured Wood Properties. A summary of measured wood properties for each species is given in Table 4 . 


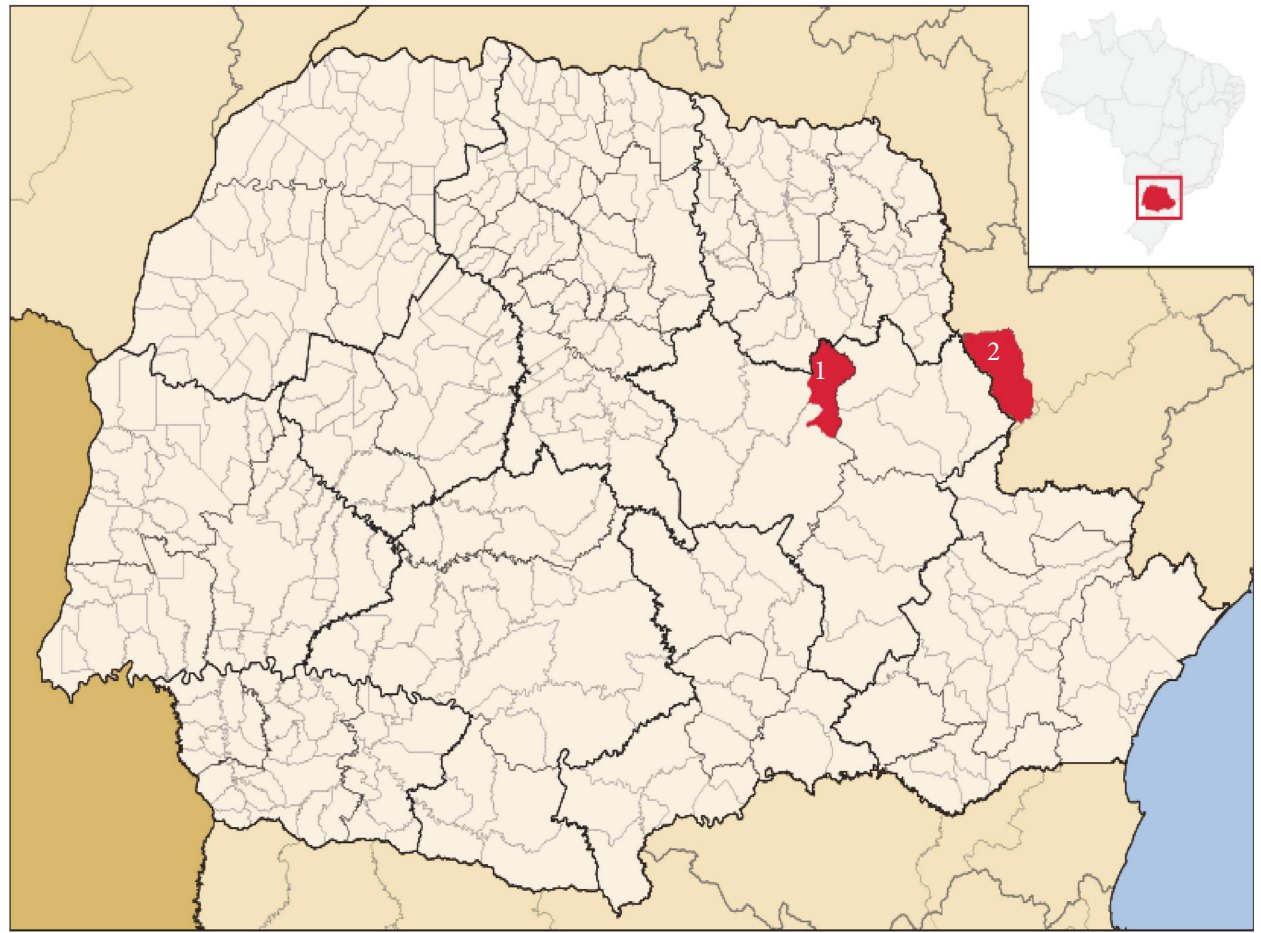

Figure 2: Location of the sites sampled: (1) Ventania, Paraná, and (2) Municipality of Itararé, Sao Paolo.

TABLE 2: Location and description of sampling sites.

\begin{tabular}{lcc}
\hline & Ventania, Paraná & Itararé, São Paulo \\
\hline Latitude $\left(^{\circ}\right)$ & $24^{\circ} 14^{\prime} 45^{\prime \prime} \mathrm{S}$ & $24^{\circ} 06^{\prime} 33^{\prime \prime} \mathrm{S}$ \\
Longitude $\left(^{\circ}\right)$ & $50^{\circ} 14^{\prime} 34^{\prime \prime} \mathrm{W}$ & $49^{\circ} 19^{\prime} 57^{\prime \prime} \mathrm{W}$ \\
Elevation (m a.s.l.) & 990 & 750 \\
Average temperature $\left({ }^{\circ} \mathrm{C}\right)$ & 22 & 25 \\
Average rainfall $(\mathrm{mm})$ & 1400 & 1300 \\
Climate & Humid subtropical & Subtropical \\
\hline
\end{tabular}

TABle 3: Average diameter (at breast height) and height for the six species sampled. One species, Pinus caribaea, included three varieties.

\begin{tabular}{lccc}
\hline Species & Age (yr) & $\begin{array}{c}\text { Diameter at breast } \\
\text { height }(\mathrm{mm})\end{array}$ & Height (m) \\
\hline $\begin{array}{l}\text { Pinus caribaea } \\
\text { var. bahamensis }\end{array}$ & 17 & 370 & 27.0 \\
$\begin{array}{l}\text { Pinus caribaea } \\
\text { var. caribaea }\end{array}$ & 17 & 370 & 26.3 \\
$\begin{array}{l}\text { Pinus caribaea } \\
\text { var. hondurensis }\end{array}$ & 18 & 420 & 25.1 \\
$\begin{array}{l}\text { Pinus chiapensis } \\
\text { Pinus maximinoi }\end{array}$ & 18 & 460 & 29.8 \\
$\begin{array}{l}\text { Pinus oocarpa } \\
\text { Pinus taeda }\end{array}$ & 18 & 470 & 27.6 \\
Pinus tecunumanii & 18 & 410 & 26.7 \\
\hline
\end{tabular}

3.2. Wood Property Calibrations. Density, MOE, and MOR calibrations obtained using transverse and radial face spectra collected using the three instrument options (Foss Direct, Foss Probe, and ASD Probe) are summarized in Tables 5, 6, and 7, respectively. All calibrations reported used the number of factors indicated by the Unscrambler software, hence comparisons are not exact; however, the number of factors used are generally similar for each property and having the number of factors identical throughout did not change the ranking of instrument options or comments related to the two wood faces examined. Some calibrations required up to 10 factors, which may be considered excessive, and is possibly the result of using untreated NIR data.

For all properties, calibrations based on Foss Direct spectra provided the strongest statistics. Density (Figure 4(a)) and MOE (Figure 4(b)) calibrations had similar $R^{2}(0.78$ to 0.81$)$ and $\mathrm{RPD}_{\mathrm{c}}$ (2.1 to 2.2) values while those for MOR (0.69 to 0.73 and 1.7 to 1.9 , resp.) were lower (Figure $4(\mathrm{c})$ ).

Of the two probe options, NIR spectra obtained using the ASD spectrophotometer consistently provided stronger calibration statistics than those obtained using spectra collected using the Foss Probe. For the ASD probe, $R^{2}$ and $R P D_{c}$ values ranged from 0.64 to 0.75 and 1.6 to 2.0 , respectively, while for the Foss Probe they ranged from 0.50 to 0.68 and 1.3 to 1.7 . Again, density and MOE calibrations were similar, while those for MOR had weaker statistics.

For a given property, and method of collecting spectra, the transverse face may be marginally better at capturing sample variability than the radial face as $\mathrm{RPD}_{\mathrm{c}}$ values are often equivalent even though fewer factors were used for the transverse face calibrations. The only instance where 


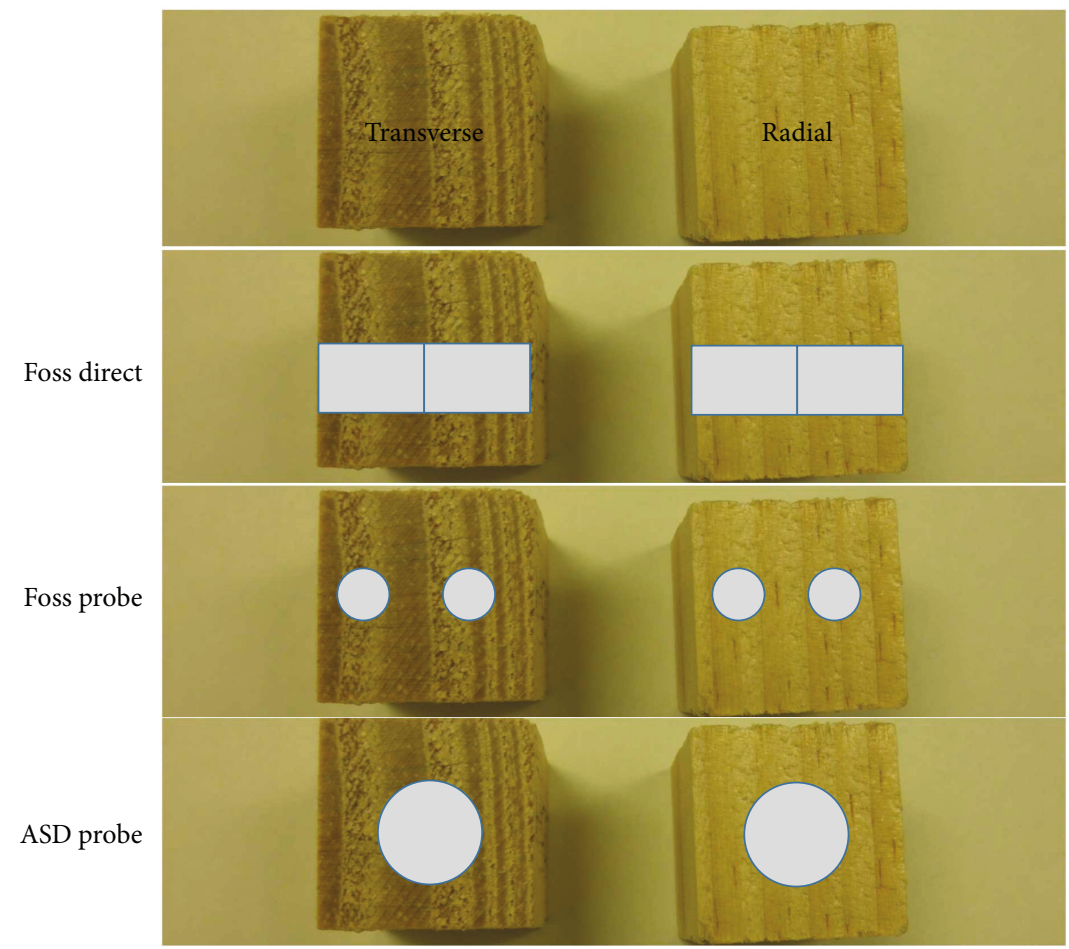

Figure 3: A typical pine sample utilized in this study. NIR spectra were collected from the transverse and radial faces, with the approximate areas examined for the different methods (Foss Direct, Foss Probe, and ASD Probe) employed for obtaining spectra highlighted.

TABLE 4: Summary information (average, standard deviation, maximum, and minimum) for density, modulus of elasticity (MOE), and modulus of rupture (MOR) values for each of the six pine species utilized in this study. One species, Pinus caribaea, included three varieties.

\begin{tabular}{|c|c|c|c|c|}
\hline Species & Samples tested & $\begin{array}{c}\text { Density }(12 \%) \\
\left(\mathrm{kg} / \mathrm{m}^{3}\right)\end{array}$ & $\begin{array}{l}\mathrm{MOE} \\
(\mathrm{MPa})\end{array}$ & $\begin{array}{l}\text { MOR } \\
(\mathrm{MPa})\end{array}$ \\
\hline \multirow{2}{*}{ P. c. bahamensis } & \multirow{2}{*}{47} & 490,89 & 7048,2668 & $64,18.6$ \\
\hline & & $(340,749)$ & $(2791,13,791)$ & $(33,104)$ \\
\hline \multirow{2}{*}{ P. c. caribaea } & \multirow{2}{*}{37} & 445,65 & 5930,2149 & 55,15 \\
\hline & & $(366,641)$ & $(2883,10,877)$ & $(26,96)$ \\
\hline \multirow{2}{*}{ P.c. hondurensis } & \multirow{2}{*}{46} & 507,112 & 7027,2250 & 59,13 \\
\hline & & $(383,1008)$ & $(3784,12,130)$ & $(38,83)$ \\
\hline \multirow{2}{*}{ P. chiapensis } & \multirow{2}{*}{50} & 444,48 & 7377,1431 & 59,10 \\
\hline & & $(360,551)$ & $(2560,10,190)$ & $(42,80)$ \\
\hline \multirow{2}{*}{ P. maximinoi } & \multirow{2}{*}{43} & 522,72 & 9011,2241 & 68,14 \\
\hline & & $(420,701)$ & $(5641,14,149)$ & $(47,103)$ \\
\hline \multirow{2}{*}{ P. oocarpa } & \multirow{2}{*}{38} & 534,92 & 7699,2791 & 66,16 \\
\hline & & $(412,699)$ & $(4035,15,433)$ & $(47,109)$ \\
\hline \multirow{2}{*}{ P. taeda } & \multirow{2}{*}{24} & 515,73 & 8015,2250 & 61,14 \\
\hline & & $(371,655)$ & $(4219,11,269)$ & $(36,88)$ \\
\hline \multirow{2}{*}{ P. tecunumanii } & \multirow{2}{*}{49} & 560,74 & 9110,2448 & 70,13 \\
\hline & & $(464,785)$ & $(5882,16,032)$ & $(48,119)$ \\
\hline
\end{tabular}

Note: P. c. = Pinus caribaea variety.

a calibration based on transverse face NIR spectra was clearly inferior to the corresponding radial face spectra was for the density calibration based on data provided by the ASD probe.

\section{Discussion}

Calibrations for density, MOE, and MOR were obtained using multiple pine species grown on two sites in southern 
TABLE 5: Summary of air-dry density calibrations based on radial and transverse face NIR spectra obtained using three different methods (Foss Direct, Foss Probe, and ASD Probe) for collecting spectral data. 332 samples were used to develop the calibrations.

\begin{tabular}{|c|c|c|c|c|c|}
\hline Property/method & Number of factors & $R^{2}$ & SEC & SECV & $\mathrm{RPD}_{\mathrm{c}}$ \\
\hline \multicolumn{6}{|c|}{ Foss Direct } \\
\hline Density $\left(\mathrm{kg} / \mathrm{m}^{3}\right)$-radial face & 8 & 0.81 & 35.6 & 38.5 & 2.1 \\
\hline Density $\left(\mathrm{kg} / \mathrm{m}^{3}\right)$-transverse face & 8 & 0.80 & 36.8 & 38.3 & 2.2 \\
\hline \multicolumn{6}{|c|}{ Foss Probe } \\
\hline Density $\left(\mathrm{kg} / \mathrm{m}^{3}\right)$-radial face & 4 & 0.51 & 57.7 & 59.8 & 1.4 \\
\hline Density $\left(\mathrm{kg} / \mathrm{m}^{3}\right)$-transverse face & 10 & 0.68 & 46.8 & 49.5 & 1.7 \\
\hline \multicolumn{6}{|c|}{ ASD Probe } \\
\hline Density $\left(\mathrm{kg} / \mathrm{m}^{3}\right)$-radial face & 8 & 0.73 & 43.2 & 45.8 & 2.0 \\
\hline Density $\left(\mathrm{kg} / \mathrm{m}^{3}\right)$-transverse face & 10 & 0.70 & 45.0 & 48.5 & 1.8 \\
\hline
\end{tabular}

TABLE 6: Summary of modulus of elasticity (MOE) calibrations based on radial and transverse face NIR spectra obtained using three different methods (Foss Direct, Foss Probe, and ASD Probe) for collecting spectral data. 334 samples were used to develop the calibrations.

\begin{tabular}{|c|c|c|c|c|c|}
\hline Property/method & Number of factors & $R^{2}$ & SEC & SECV & $\mathrm{RPD}_{\mathrm{c}}$ \\
\hline \multicolumn{6}{|c|}{ Foss Direct } \\
\hline MOE (MPa)-radial face & 8 & 0.78 & 1154 & 1215 & 2.1 \\
\hline MOE (MPa)-transverse face & 6 & 0.81 & 1095 & 1124 & 2.2 \\
\hline \multicolumn{6}{|c|}{ Foss Probe } \\
\hline MOE (MPa)-radial face & 7 & 0.55 & 1668 & 1727 & 1.4 \\
\hline MOE (MPa)-transverse face & 10 & 0.71 & 1342 & 1431 & 1.7 \\
\hline \multicolumn{6}{|c|}{ ASD Probe } \\
\hline MOE (MPa)_radial face & 9 & 0.73 & 1308 & 1413 & 1.8 \\
\hline MOE (MPa)-transverse face & 6 & 0.75 & 1252 & 1303 & 1.7 \\
\hline
\end{tabular}

TABLE 7: Summary of modulus of rupture (MOR) based on radial and transverse face NIR spectra obtained using three different methods (Foss Direct, Foss Probe, and ASD Probe) for collecting spectral data. 334 samples were used to develop the calibrations.

\begin{tabular}{|c|c|c|c|c|c|}
\hline Property/method & Number of factors & $R^{2}$ & SEC & SECV & $\mathrm{RPD}_{\mathrm{c}}$ \\
\hline \multicolumn{6}{|c|}{ Foss Direct } \\
\hline MOR $(\mathrm{MPa})$-radial face & 4 & 0.69 & 8.4 & 8.6 & 1.7 \\
\hline MOR $(\mathrm{MPa})$-transverse face & 6 & 0.73 & 7.9 & 8.0 & 1.9 \\
\hline \multicolumn{6}{|c|}{ Foss Probe } \\
\hline MOR $(\mathrm{MPa})$-radial face & 7 & 0.50 & 10.6 & 11.2 & 1.3 \\
\hline MOR $(\mathrm{MPa})$-transverse face & 10 & 0.61 & 9.3 & 10.3 & 1.4 \\
\hline \multicolumn{6}{|c|}{ ASD Probe } \\
\hline MOR (MPa)_radial face & 8 & 0.67 & 8.6 & 9.2 & 1.6 \\
\hline MOR (MPa)-transverse face & 5 & 0.64 & 9.0 & 9.2 & 1.6 \\
\hline
\end{tabular}

Brazil. Calibrations were based on NIR spectra collected using three different approaches (Foss Direct, Foss Probe, and ASD Probe) and from two different wood surfaces (radial and transverse). The strong calibration statistics obtained for models using the Foss Direct and ASD Probe methods demonstrates the potential for general calibrations for estimating wood properties of a number of tropical, subtropical, and temperate pine species. The multiple species calibrations may not be as accurate as those based on a single site or species but are sufficient to rank samples [26].
Comparison of the different spectroscopic approaches used to collect spectra indicated that the Direct approach provided stronger calibration statistics than either of the Probe methods. The advantage of using the Direct approach is that the sample is exposed directly to the NIR beam (whether it is placed directly on the instrument aperture or against a Teflon window) rather than having to transmit the beam through a fiber-optic cable which causes noise in the signal beyond $2300 \mathrm{~nm}$. However, to utilize a Direct approach, subsamples were often removed from the end of 


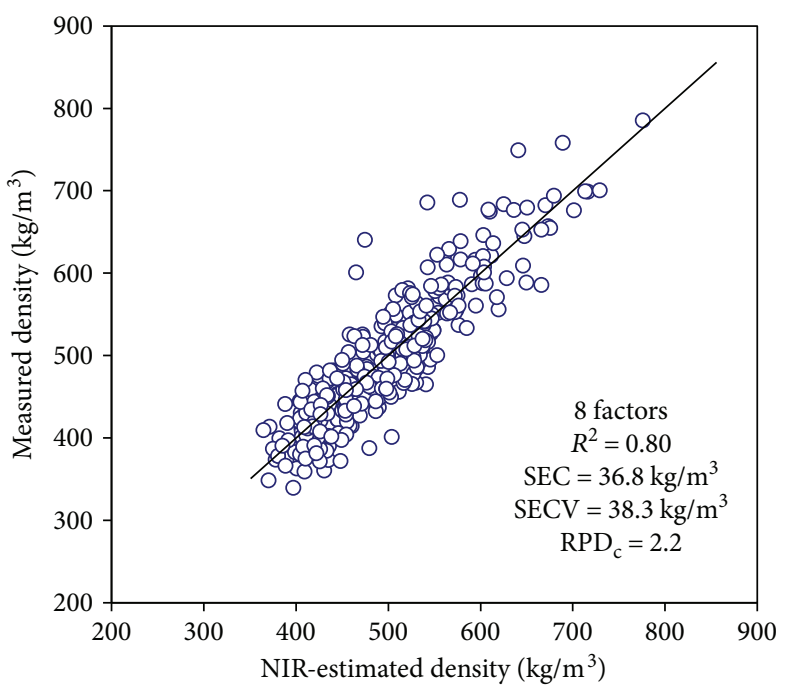

(a)

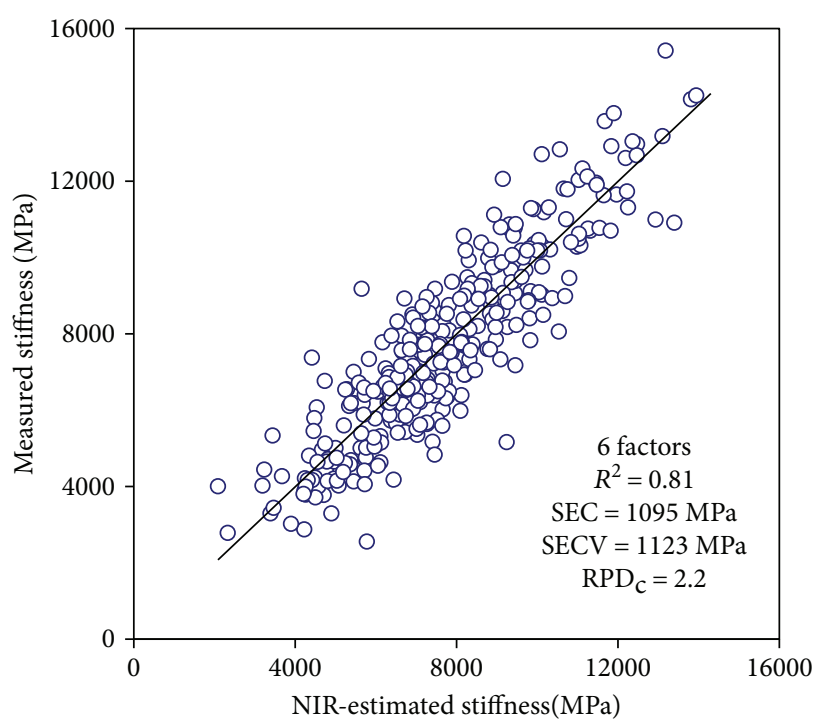

(b)

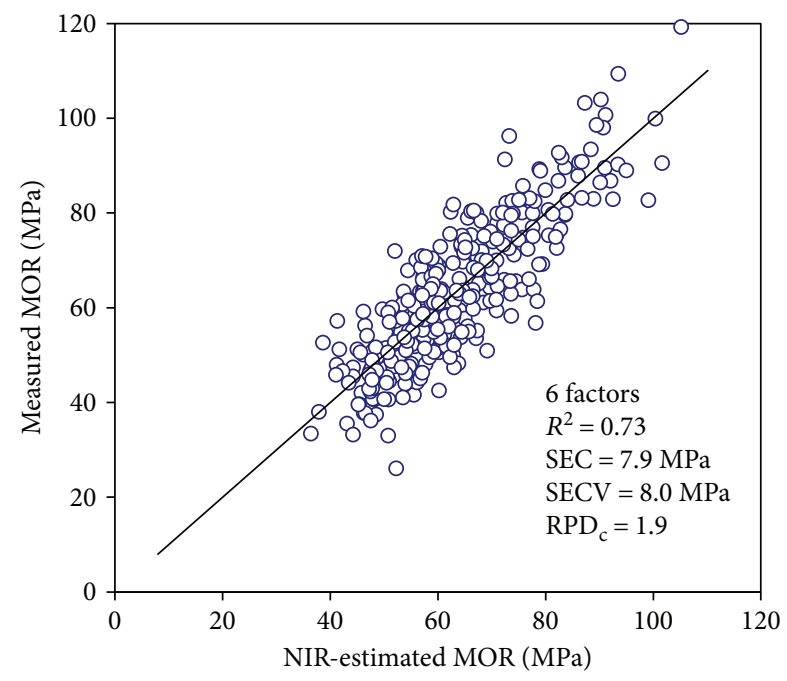

(c)

FIGURE 4: Relationship between lab-measured wood properties and NIR-fitted wood properties, (a) density, (b) modulus of elasticity (MOE), and (c) modulus of rupture (MOR). The broken line represents the line of equivalence. 332 samples were used to develop the density calibration, while 334 samples were used to develop the calibrations for MOE and MOR.

the short clear sample to allow the sample to be tested by the NIR instrument $[13,16,21]$. In comparison, utilization of the Probe approach provides much greater flexibility for testing samples [12, 15], and cutting the static bending sample is not required.

When comparing the ASD and Foss Probe spectra, the ASD instrument provided stronger calibrations for all properties. A critical factor in the success of the ASD Probe method was the greater surface area covered by the ASD probe compared to the Foss probe (Figure 3). Owing to its spot size, the ASD probe was able to capture more sample variability, that is, variation in earlywood and latewood components of individual rings, while it was not possible to achieve the same coverage when collecting two spectra using the Foss probe. Using a probe with a large diameter that approaches the width of the static bending sample also offers greater consistency in NIR measurements. For the smaller Foss probe, identification of sampling points was problematic as it always had the potential to over or under selection of latewood, which is critical in determining density and MOE [27].

An examination of related NIR studies shows that many authors either attempted to collect spectra across the complete surface of the sample, for example, Thumm and Meder [7], using a $20 \mathrm{~mm}$ wide window for samples having radial and tangential dimensions of $20 \mathrm{~mm}$, or were mindful of the cumulative area they were testing, for example, Gindl et al. [6], noting that three spectra from different locations on the radial face of their samples covered two-thirds of the radial width. In other studies [10-12, 14, 19], radial width of static bending samples varied as the authors wished to include at least three growth rings in their samples 
introducing the possibility that NIR spectra collected from wider samples underrepresented the sample compared to the same number of spectra collected from narrower samples. While its significance is unclear, a related issue was encountered by Lestander et al. [19] who noted that because of variation in the width of the target rings, spectral information from the nearest adjacent rings were occasionally included in the collected spectra.

The transverse face had marginally better results regardless of the method used to collect spectra. The only other study that attempted to compare mechanical/physical property calibrations based on spectra collected from radial and transverse surfaces was Schimleck et al.'s study [13] who also reported similar results for the two surfaces. Other studies have compared calibrations based on radial and tangential surface NIR spectra. Thumm and Meder [7] reported MOE calibrations for radial and tangential face spectra (moving face) and found much better statistics for radial face data as did Zhao et al. [20] in their study of E. pellita. In comparison, Kothiyal and Raturi [21] reported similar calibrations for both radial and tangential face spectra obtained from $E$. tereticornis static bending samples. In a more recent study, Kothiyal et al. [23] reported calibrations based on radial and tangential surface spectra and calibrations based on an average of the two. Radial face spectra provided the strongest calibrations; however, the authors concluded that "the composite model is just as good as the radial and tangential face models and can adequately address the problem where it is difficult to obtain perfect radial or tangential surface, particularly in small girth plantation timber or where surface recognition is difficult." One solution to the issue noted by Kothiyal et al. [23] is to utilize the transverse surface. In this study, tangential surface spectra were not collected owing to doubts about how well the surface would represent samples with straight grain (i.e., clear radial and tangential surfaces, as shown in Figure 1). As noted by Dahlen et al. [28], tangential face NIR spectra could easily under- or overestimate properties based on whether an earlywood or latewood component of a ring was present where the spectrum was collected.

Despite the strength of relationships reported in the various studies over the last $20+$ years, it is unlikely that NIRestimated MOE and MOR will replace the standard method used to determine these properties. However, NIR technology can complement the standard methods, for example, to measure applied loads [15], or in applications where the accuracy of a single value is not critical. Examples include studies of within-tree variation in MOE [29] or regional variation in MOE and MOR [30]. In such studies, the use of NIR-estimated values can greatly improve approximations of how properties vary spatially. The success of research based on static bending samples has also led to studies aimed at estimating properties of lumber $[18,28,31-34]$. The issue of collecting representative spectra again exists, but results are promising and owing to its ability to estimate a range of properties simultaneously [33] NIR could have an important role in sawmills in the future. In related research, the assessment of MOE and load for wood in service has recently been demonstrated [35-37].

\section{Conclusions}

NIR-based calibrations for the estimation of density, modulus of elasticity (MOE), and modulus of rupture (MOR) were developed using clear wood samples obtained from several tropical, subtropical, and temperate pine species growing on two plantation sites in Brazil. NIR spectra were collected using a benchtop instrument, a benchtop instrument with fiber-optic probe, and a field portable fiber-optic probe instrument and from two different wood surfaces (radial and transverse).

Comparison of calibrations found that the benchtop instrument provided superior results, while for the fiberoptic probe systems, the field portable NIR outperformed the benchtop probe system. Difficulty with adequately representing the sample when collecting spectra using a fiber-optic probe and lower quality spectra explain the differences among the data sets.

NIR spectra collected from the radial and transverse faces provided similar calibration statistics.

\section{Disclosure}

The work described in this paper was presented at the 65th Forest Products Society International Convention, Portland, Oregon, USA, 19-21 June 2011.

\section{Conflicts of Interest}

The authors declare that they have no competing interests.

\section{Acknowledgments}

The authors acknowledge the financial support for this research provided by the Conselho Nacional de Desenvolvimento Científico e Tecnológico (CNPq), Brazil.

\section{References}

[1] C. A. Raymond, "Genetics of Eucalyptus wood properties," Annals of Forest Science, vol. 59, no. 5-6, pp. 525-531, 2002.

[2] L. R. Schimleck, "Near infrared spectroscopy: a rapid, nondestructive method for measuring wood properties and its application to tree breeding," New Zealand Journal of Forestry Science, vol. 38, no. 1, pp. 14-35, 2008.

[3] S. Tsuchikawa, "A review of recent near infrared research for wood and paper," Applied Spectroscopy Reviews, vol. 42, no. 1, pp. 43-71, 2007.

[4] S. Tsuchikawa and H. Kobori, "A review of recent application of near infrared spectroscopy to wood science and technology," Journal of Wood Science, vol. 61, no. 3, pp. 213-220, 2015.

[5] P. Hoffmeyer and J. G. Pedersen, "Evaluation of density and strength of Norway spruce wood by near-infrared reflectance spectroscopy," Holz Als Roh-Und Werkstoff, vol. 53, no. 1, pp. 165-170, 1995.

[6] W. Gindl, A. Teischinger, M. Schwanninger, and B. Hinterstoisser, "The relationship between near infrared spectra of radial wood surfaces and wood mechanical properties," Journal of Near Infrared Spectroscopy, vol. 9, no. 1, pp. $255-261,2001$. 
[7] A. Thumm and R. Meder, "Stiffness prediction of radiata pine clearwood test pieces using near infrared spectroscopy," Journal of Near Infrared Spectroscopy, vol. 9, no. 1, pp. 117-122, 2001.

[8] L. R. Schimleck, R. Evans, and J. Ilic, "Estimation of Eucalyptus delegatensis wood properties by near infrared spectroscopy," Canadian Journal of Forest Research, vol. 31, no. 10, pp. 1671-1675, 2001.

[9] L. R. Schimleck, R. Evans, and A. C. Matheson, "Estimation of Pinus radiata D. Don clear wood properties by near-infrared spectroscopy," Journal of Wood Science, vol. 48, no. 2, pp. 132-137, 2002.

[10] B. K. Via, T. Shupe, L. Groom, M. Stine, and C.-L. So, "Multivariate modelling of density, strength and stiffness from near infrared spectra for mature, juvenile and pith wood of longleaf pine (Pinus palustris)," Journal of Near Infrared Spectroscopy, vol. 11, no. 1, pp. 365-378, 2003.

[11] S. S. Kelley, T. G. Rials, R. Snell, L. H. Groom, and A. Sluiter, "Use of near infrared spectroscopy to measure the chemical and mechanical properties of solid wood," Wood Science and Technology, vol. 38, no. 4, pp. 257-276, 2004.

[12] S. S. Kelley, T. G. Rials, L. R. Groom, and C.-L. So, "Use of near infrared spectroscopy to predict the mechanical properties of six softwoods," Holzforschung, vol. 58, no. 3, pp. 252-260, 2004.

[13] L. R. Schimleck, P. D. Jones, A. Clark, R. F. Daniels, and G. F. Peter, "Near infrared spectroscopy for the nondestructive estimation of clear wood properties of Pinus taeda L. from the southern United States," Forest Products Journal, vol. 55, no. 12, pp. 21-28, 2005.

[14] B. K. Via, C.-L. So, T. Shupe, L. Eckhardt, M. Stine, and L. Groom, "Prediction of wood mechanical and chemical properties in the presence and absence of blue stain using two near infrared instruments," Journal of Near Infrared Spectroscopy, vol. 13, no. 1, pp. 201-212, 2005.

[15] N. Andre, N. Labbé, T. G. Rials, and S. S. Kelley, "Assessment of wood load condition by near infrared (NIR) spectroscopy," Journal of Materials Science, vol. 41, no. 7, pp. 1879-1886, 2006.

[16] E. Y. Haartveit and P. O. Flæte, "Rapid prediction of basic wood properties by near infrared spectroscopy," New Zealand Journal of Forestry Science, vol. 36, no. 2/3, p. 393, 2006.

[17] T. Fujimoto, H. Yamamoto, and S. Tsuchikawa, "Estimation of wood stiffness and strength properties of hybrid larch by nearinfrared spectroscopy," Applied Spectroscopy, vol. 61, no. 8, pp. 882-888, 2007

[18] T. Fujimoto, Y. Kurata, K. Matsumoto, and S. Tsuchikawa, "Application of near infrared spectroscopy for estimating wood mechanical properties of small clear and full length lumber specimens," Journal of Near Infrared Spectroscopy, vol. 16, no. 6, pp. 529-537, 2008.

[19] T. A. Lestander, J. Lindeberg, D. Eriksson, and U. Bergsten, "Prediction of Pinus sylvestris clear-wood properties using NIR spectroscopy and biorthogonal partial least squares regression," Canadian Journal of Forest Research, vol. 38, no. 7, pp. 2052-2062, 2008.

[20] R. J. Zhao, X. M. Huo, and L. Zhang, "Estimation of modulus of elasticity of Eucalyptus pellita wood by near infrared spectroscopy," Spectroscopy and Spectral Analysis, vol. 29, no. 9, pp. 2392-2395, 2009.

[21] V. Kothiyal and A. Raturi, "Estimating mechanical properties and specific gravity for five-year-old Eucalyptus tereticornis having broad moisture content range by NIR spectroscopy," Holzforschung, vol. 65, no. 5, pp. 757-762, 2011.

[22] L. R. Schimleck, J. L. M. de Matos, J. T. da Silva Oliveira, and G. I. B. Muniz, "Non-destructive estimation of pernambuco (Caesalpinia echinata) clear wood properties using near infrared spectroscopy," Journal of Near Infrared Spectroscopy, vol. 19, no. 5, pp. 411-419, 2011.

[23] V. Kothiyal, A. Raturi, Jaideep, and Y. M. Dubey, "Enhancing the applicability of near infrared spectroscopy for estimating specific gravity of green timber from Eucalyptus tereticornis by developing composite calibration using both radial and tangential face of wood," European Journal of Wood and Wood Products, vol. 72, no. 1, pp. 11-20, 2014.

[24] COPANT, 555 Método de ensayo de flexion estatica, Comisión Panamericana de Normas Técnicas (Pan American Standards Commission), 1972.

[25] P. C. Williams and D. C. Sobering, "Comparison of commercial near infrared transmittance and reflectance instruments for analysis of whole grains and seed," Journal of Near Infrared Spectroscopy, vol. 1, no. 1, p. 8, 1993.

[26] L. R. Schimleck, G. R. Hodge, and W. Woodbridge, “Toward global calibrations for estimating the wood properties of tropical, sub-tropical and temperate pine species," Journal of Near Infrared Spectroscopy, vol. 18, no. 6, pp. 355-365, 2010.

[27] L. Jordan, A. Clark, L. R. Schimleck, D. B. Hall, and R. F. Daniels, "Regional variation in wood specific gravity of planted loblolly pine in the United States," Canadian Journal of Forest Research, vol. 38, no. 4, pp. 698-710, 2008.

[28] J. Dahlen, I. Diaz, L. Schimleck, and P. D. Jones, "Near-infrared spectroscopy prediction of southern pine no. 2 lumber physical and mechanical properties," Wood Science and Technology, vol. 51, no. 2, pp. 309-322, 2017.

[29] C. R. Mora and L. R. Schimleck, "Determination of within-tree variation of Pinus taeda wood properties by near infrared spectroscopy. Part 2: whole-tree wood property maps," Appita Journal, vol. 62, no. 3, pp. 232-238, 2009.

[30] F. Antony, L. Jordan, L. R. Schimleck, A. Clark III, R. A. Souter, and R. F. Daniels, "Regional variation in wood modulus of elasticity (stiffness) and modulus of rupture (strength) of planted loblolly pine in the United States," Canadian Journal of Forest Research, vol. 41, no. 7, pp. 1522-1533, 2011.

[31] R. Meder, A. Thumm, and D. Marston, "Sawmill trial of at-line prediction of recovered lumber stiffness by NIR spectroscopy of Pinus radiata cants," Journal of Near Infrared Spectroscopy, vol. 11, no. 1, pp. 137-143, 2003.

[32] T. Fujimoto, Y. Kurata, K. Matsumoto, and S. Tsuchikawa, "Feasibility of near-infrared spectroscopy for on-line grading of sawn lumber," Applied Spectroscopy, vol. 64, no. 1, pp. 92-99, 2010.

[33] T. Fujimoto, Y. Kurata, K. Matsumoto, and S. Tsuchikawa, "Feasibility of near-infrared spectroscopy for online multiple trait assessment of sawn lumber," Journal of Wood Science, vol. 56, no. 6, pp. 452-459, 2010.

[34] H. Kobori, T. Inagaki, T. Fujimoto, T. Okura, and S. Tsuchikawa, "Fast online NIR technique to predict MOE and moisture content of sawn lumber," Holzforschung, vol. 69, no. 3, pp. 329-335, 2015.

[35] M. Riggio, J. Sandak, A. Sandak, D. Pauliny, and L. Babiński, "Analysis and prediction of selected mechanical/dynamic properties of wood after short and long-term waterlogging," Construction and Building Materials, vol. 68, pp. 444454, 2014. 
[36] A. Sandak, J. Sandak, and M. Riggio, "Estimation of physical and mechanical properties of timber members in service by means of infrared spectroscopy," Construction and Building Materials, vol. 101, pp. 1197-1205, 2015.

[37] A. Sandak, J. Sandak, and M. Riggio, “Assessment of wood structural members degradation by means of infrared spectroscopy: an overview," Structural Control and Health Monitoring, vol. 23, no. 3, pp. 396-408, 2016. 

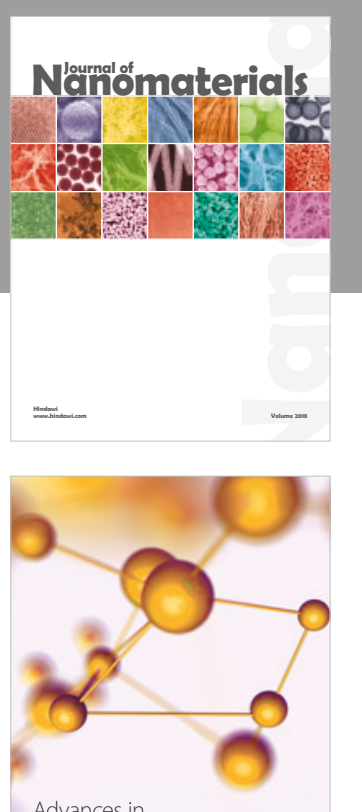

Physical Chemistry
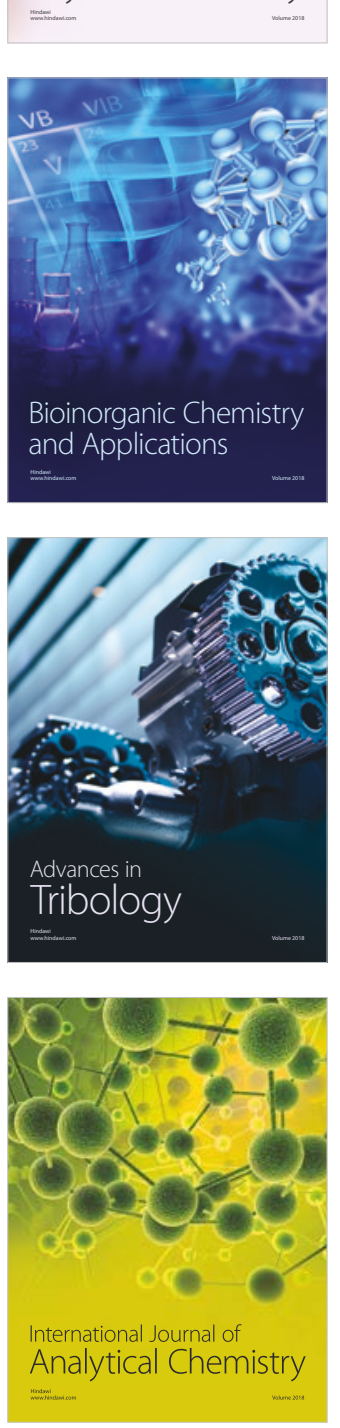

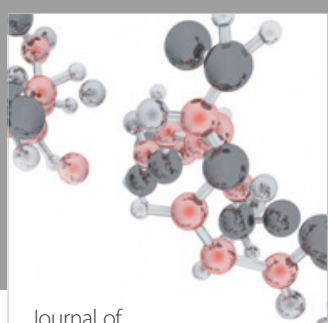

Analytical Methods

in Chemistry

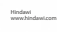

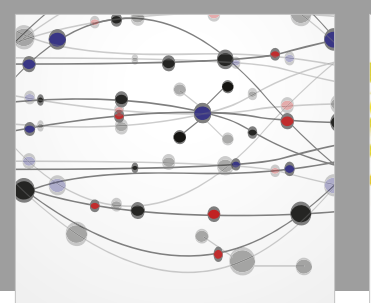

The Scientific World Journal

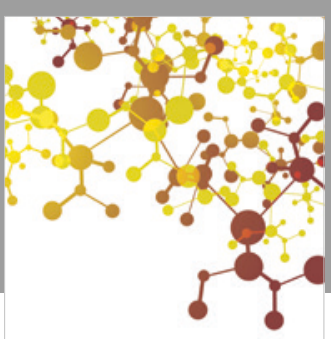

Journal of

Applied Chemistry
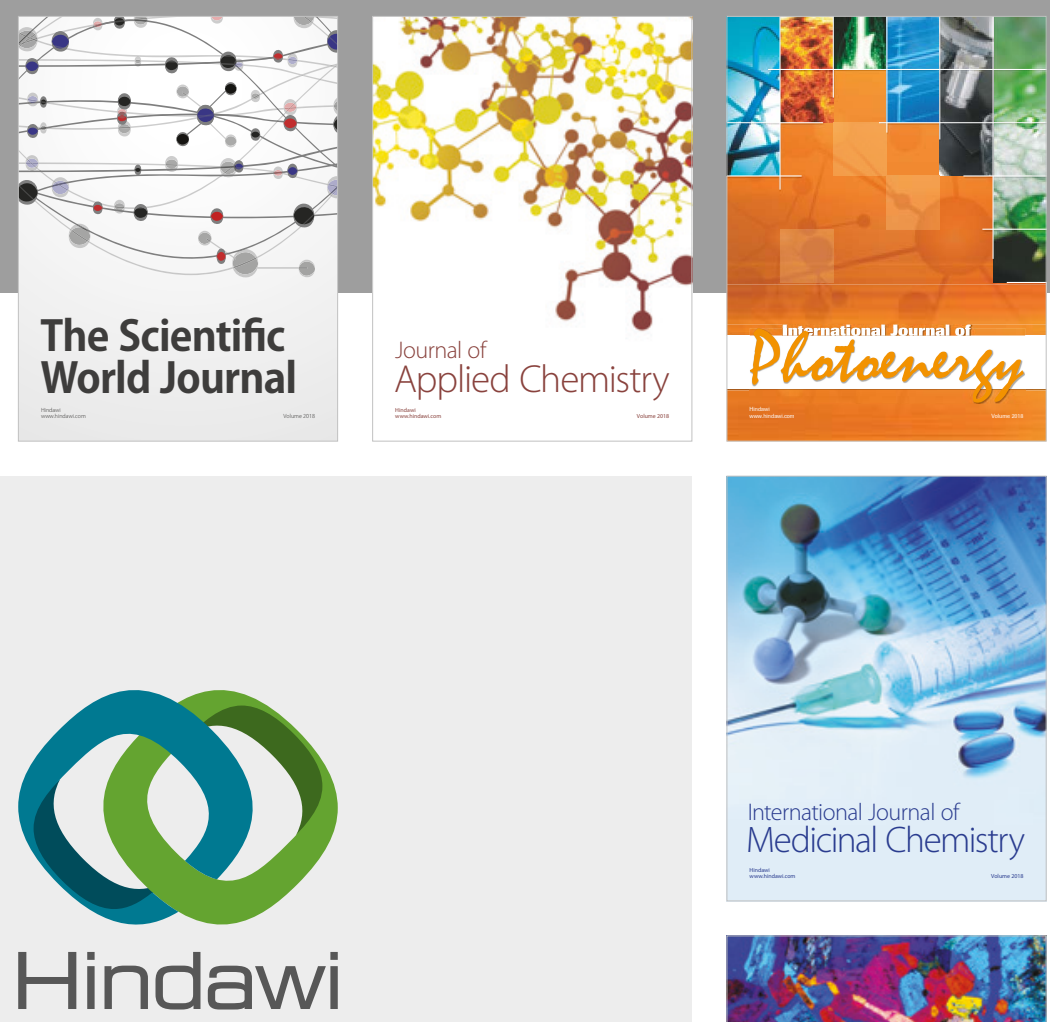

Submit your manuscripts at

www.hindawi.com
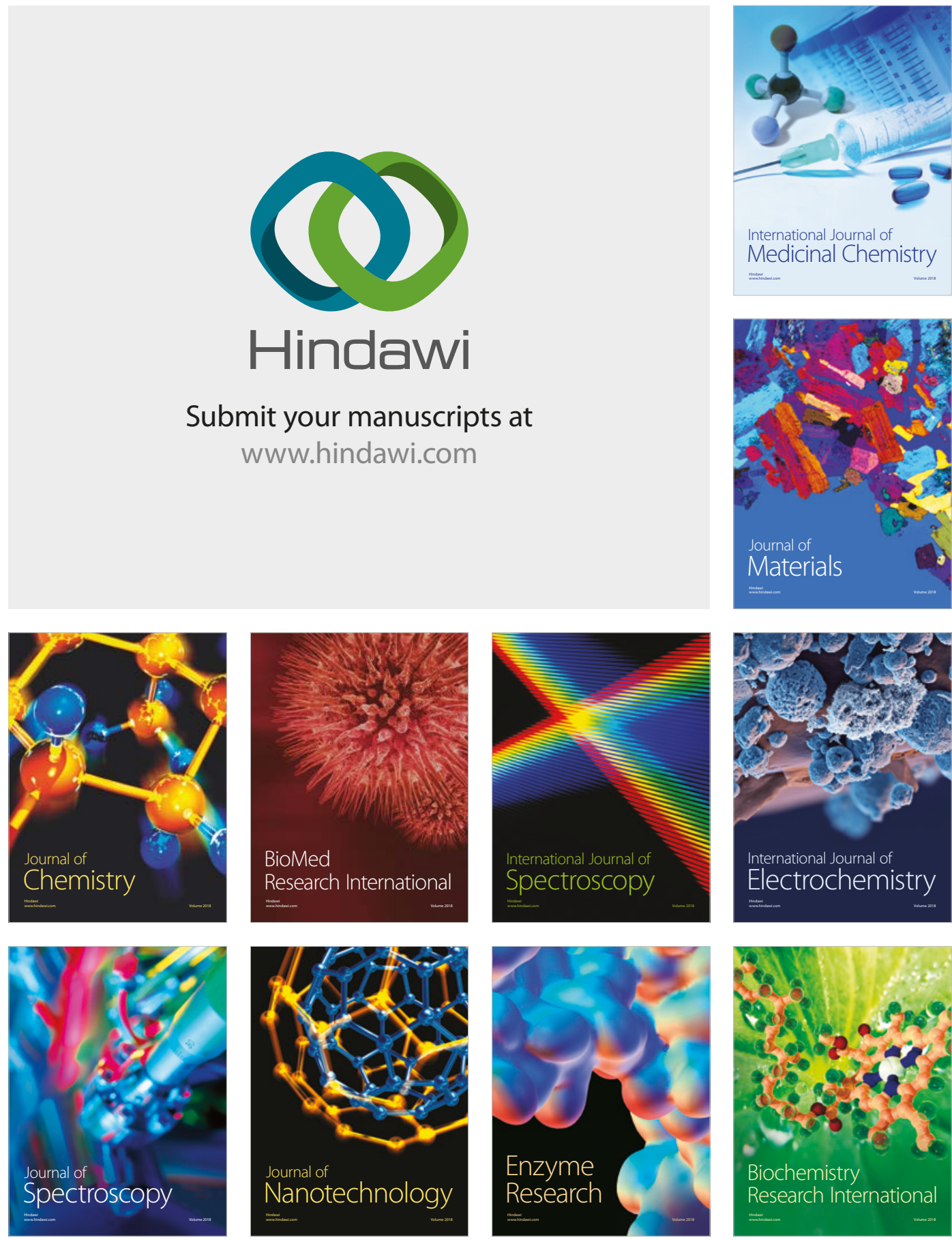
